\title{
Pathways Connecting Late-Life Depression and Dementia
}

\author{
Christoph Linnemann* and Undine E. Lang \\ University of Basel, Universitäre Psychiatrische Kliniken (UPK), Basel, Switzerland
}

Late-life depression is associated with significant cognitive impairment. Meta-analyses showed that depression is associated with an increased risk for Alzheimer's disease $(A D)$ and it might be an etiological factor for AD. Since late-life depression is often connected with cognitive impairment and dementia is usually associated with depressive symptoms, a simple diagnostic approach to distinguish between the disorders is challenging. Several overlapping pathophysiological substrates might explain the comorbidity of both syndromes. Firstly, a stress syndrome, i.e., elevated cortisol levels, has been observed in up to $70 \%$ of depressed patients and also in AD pathology. Stress conditions can cause hippocampal neuronal damage as well as cognitive impairment. Secondly, the development of a depression and dementia after the onset of vascular diseases, the profile of cerebrovascular risk factors in both disorders and the impairments depending on the location of cerebrovascular lesions, speak in favor of a

OPEN ACCESS

Edited by:

Lydia Gimenez-Llort, Autonomous University of Barcelona,

Spain

Reviewed by:

Stephen D. Ginsberg,

The Nathan S. Kline Institute for Psychiatric Research, United States

Bruno P. Imbimbo,

Chiesi Farmaceutici, Italy

*Correspondence:

Christoph Linnemann christoph.linnemann@upk.ch

Specialty section: This article was submitted to

Neuropharmacology,

a section of the journal

Frontiers in Pharmacology

Received: 16 December 2019

Accepted: 26 February 2020

Published: 13 March 2020

Citation:

Linnemann C and Lang UE (2020) Pathways Connecting Late-Life Depression and Dementia. Front. Pharmacol. 11:279. doi: 10.3389/fphar.2020.00279 vascular hypothesis as a common factor for both disorders. Thirdly, neuroinflammatory processes play a key role in the etiology of depression as well as in dementia. Increased activation of microglia, changes in Transforming-Growth-Factor beta1 (TGF-beta1) signaling, production of pro-inflammatory cytokines as well as reduction of antiinflammatory molecules are examples of common pathways impaired in dementia and depression. Fourthly, the neurotrophin BDNF is highly expressed in the central nervous system, especially in the hippocampus, where it plays a key role in the proliferation, differentiation and the maintenance of neuronal integrity throughout lifespan. It has been associated not only with antidepressant properties but also a reduction of cognitive impairment and therefore could be involved also in AD. Another etiologic factor is amyloid accumulation, as plasma amyloid beta-42 independently predicts both lateonset depression and AD. Higher plasma amyloid beta-42 predicts the development of late onset depression and conversion to possible AD. However, clinical trials with antibodies against beta amyloid recently failed, i.e., Solanezumab, Aducanumab, and Crenezumab. An overproduction of amyloid-beta might simply reflect a form of synaptic plasticity to compensate for neuronal dysfunction in different kind of neurological and psychiatric diseases of multiple etiologies. The tau hypothesis, sex/gender specific differences, epigenetics and the gut microbiota-brain axis imply other potential common pathways connecting late-life depression and dementia. In conclusion, different potential pathophysiological links between dementia and depression highlight several specific synergistic and multifaceted treatment possibilities, depending on the individual risk profile of the patient.

Keywords: late-life depression, dementia, endocrine hypothesis, vascular hypothesis, neuroinflammation, amyloid hypothesis 


\section{INTRODUCTION}

Older adults with late-life depression often suffer from serious cognitive impairment without full recovery after successful antidepressant treatment. A relationship has been shown between history of depression and increased risk of dementia. Recent meta-analyses found that depression was associated with an increased risk for dementia and Alzheimer's disease (AD).

Dementia is a clinical syndrome characterized by a progressive deterioration of cognitive function associated with impairment in activities of daily living (van der Flier and Scheltens, 2005) commencing mostly in late life. It is estimated that there will be approximately 4.6 million new cases every year worldwide, doubling every 20 years to 81.1 million by 2040 (Ferri et al., 2005). It is increasing in high-income countries and even more so in low- and middle-income countries (Kalaria et al., 2008). In late life the prevalence of depression is expected to rise and thus denotes new challenges for the mental health system. Mutual hypotheses to explain comorbidity suggest that depression might either be an early symptom of dementia, or a reaction to cognitive decline, or due to an overlap of both syndromes. Other hypotheses suggest that depression might increase susceptibility to dementia or act as a predictor, if not a causal factor for dementia (Lenoir et al., 2011). So far, no particular and distinctive symptom profile with substantial usefulness in the clinical setting has emerged as characteristic of late-life depression (Gallagher et al., 2010). More importantly, the intensity and the reporting of depressive symptoms in the elderly are suspected to be covert and not properly meeting the diagnostic criteria. Since latelife depression is often coupled with cognitive impairment and dementia may be associated with depressive symptoms, a simple differential diagnostic approach to distinguish between those syndromes is not always possible (Steffens and Potter, 2008). Depressive symptoms are reported in $30-50 \%$ of $\mathrm{AD}$ patients (Zubenko et al., 2003) and severe depressive episodes are reported in more than $10 \%$ of patients suffering from $\mathrm{AD}$ (Lopez et al., 2003) and in about 50\% of patients with vascular dementia (Ballard et al., 2000; Park et al., 2007). The definitions of the terms "depression" and "dementia" are heterogeneous with blurred boundaries. Depression and dementia are not dichotomous symptoms or diagnoses. Depression can be considered as a symptom of dementia. Neuropsychiatric symptoms or behavioral and psychological symptoms are almost universal parts of dementia, as reviewed by van der Linde et al. (2016). The Cache County Study (Steinberg et al., 2008) revealed point and 5-year period prevalence of neuropsychiatric symptoms in dementia and found that participants most likely developed depression (77\%), apathy (71\%) and anxiety (62\%). A 5year longitudinal study of 223 patients with mild dementia and annual assessments in Western Norway (Vik-Mo et al., 2018) revealed that the most common symptoms were apathy (83\%), depression (63\%), appetite (63\%), and aberrant motor behavior (60\%). Connors et al. (2018) investigated the stability of neuropsychiatric subsyndromes in $\mathrm{AD}$ by principal component analyses and multiple-group confirmatory factor analyses. The findings suggest that the neuropsychiatric symptoms do not appear in distinctive subsyndromes that are stable over time. Neuropsychiatric symptoms in dementia have multiple overlapping relationships with one another. It is well-known that cognitive decline limits language skills as well as self-awareness of depressive symptoms. Depression and apathy due to dementia are difficult to differentiate. The problem of the correct diagnosis is foreshadowed by the large range of published prevalence rates for depression in $\mathrm{AD}$ from under 5\% to nearly 50\% (Weiner et al., 1994, 2002). Forgetfulness, difficulties in concentration, sleeping too much or not enough, reducing social contacts as well as loss of interest in hobbies mark additional areas of overlap for depression and dementia. Clinically, depression may masquerade as dementia, dementia may pose as depression, and dementia and depression may coexist. Neuropsychological tests and psychiatric exploration may not differentiate between reversible cognitive deficits due to depression and persistent cognitive impairment due to dementia. Widely used rating scales - in studies as well as in clinical daily routine - assessing the severity of depression are not always helpful for demented patients. The MontgomeryAsberg Depression Rating Scale - MADRS (Montgomery and Asberg, 1979) is not validated for demented patients (Holroyd and Clayton, 2000; Conn and Thorpe, 2007). The Hamilton Depression Rating Scale - HAM-D (Hamilton, 1960) has not been validated in severely demented patients (Lichtenberg et al., 1992). Interestingly, antidepressant drugs have proven efficacy in non-demented populations (Cipriani et al., 2018), but revealed negative outcomes in randomized placebo-controlled trials with antidepressants in dementia (Leong, 2014; Leyhe et al., 2017): venlafaxine (75 mg daily) for 6 weeks, assessed by MADRS in 31 patients (de Vasconcelos Cunha et al., 2007); fluoxetine (maximum $40 \mathrm{mg}$ daily) for 6 weeks, assessed by HAM-D in 41 patients (Petracca et al., 2001) and imipramine (83 mg daily) for 8 weeks, assessed by HAM-D in 61 patients (Reifler et al., 1989). Pharmacological interventions based on serotonergic and noradrenergic etiology were mostly disappointing. A promising overlap between dementia and depression might be the glutamatergic signaling, namely the dysfunction of $N$-methyl-D-aspartate (NMDA) receptor complex signaling. NMDA receptor antagonists feature antidementia and antidepressant potential [for review see Khundakar and Thomas (2015)]. In a review by Butters et al. (2008), the hypothesis has been postulated that depression leads to subsequent cognitive impairment and dementia.

\section{THE ENDOCRINE HYPOTHESIS}

One of the most important endocrine components to respond to stress is the secretion of corticosteroid hormones. The neuroendocrinology of depressive patients - as far as the hypothalamic-pituitary adrenal (HPA) axis is concerned - shares common characteristics with that of rats that are chronically stressed (Checkley, 1996). Moreover, there is evidence for an increased central HPA axis activation in animal models of chronic stress (Herman et al., 1989; Angulo et al., 1991; de Goeij et al., 1992; Bartanusz et al., 1993; Harbuz et al., 1993) as well as in human depression (Ur et al., 1992; Raadsheer et al., 1994; Young et al., 1994). Secondly, the impaired negative feedback can be 
observed in animal models of chronic stress (Sapolsky et al., 1984; Young et al., 1990) as well as in depression (Carroll et al., 1981; Young et al., 1991). Thirdly, the hypertrophy of the adrenal gland can be found in chronically stressed animals (Herman et al., 1995) as well as in depressive patients (Dorovini-Zis and Zis, 1987; Nemeroff et al., 1992; Rubin et al., 1995). In line with these observations, the dexamethasone suppression test can be striking in depressive patients (Arana and Mossman, 1988). The hippocampus contains corticosteroid receptors (McEwen, 1999). Stress conditions as well as an exogenous application of glucocorticoids can cause hippocampal neuronal damage as well as cognitive impairment (Levy et al., 1994; Cereseto et al., 2006). Stress exposure causes volume reductions of the hippocampus, impairs dendritic complexity of neurons in the CA3 and affects neurogenesis in the dentate gyrus (Gould et al., 2000; Czeh and Lucassen, 2007). Increased levels of cortisol serum are associated with AD biomarkers in CSF and serum cortisol and CSF tau levels are negatively correlated (Laske et al., 2009). Similarly, hyperactivation of the hypothalamic-pituitary-adrenal (HPA) axis and increased levels of cortisol are most consistently observed findings in up to $70 \%$ of depressed patients (Porcelli et al., 2011). Impaired hippocampal plasticity may be related to cognitive impairment due to depression. A large number of MRI studies investigated the hippocampus subfield volumetrics in depressive patients compared to controls: As summarized by Maller et al. (2018), the findings were partly inconsistent. No significant differences concerning various hippocampal subfields in depressive patients compared to controls or correlations with illness duration or number of episodes have been found (Cho et al., 2010; Cole et al., 2010; Huang et al., 2013; Lindqvist et al., 2014; Na et al., 2014; Travis et al., 2015; Treadway et al., 2015; Han et al., 2016; Maller et al., 2018). Hippocampal tail volume was discussed as being a biomarker for sensitivity to treatment with antidepressant medication (Maller et al., 2018). The association of hippocampal volume and dementia, especially $\mathrm{AD}$, is well known and has been refined several times (Allison et al., 2019).

\section{THE VASCULAR HYPOTHESIS}

Clinically, the onset or worsening of a depression after the onset of vascular disease, the profile of cerebrovascular risk factors in depressive patients, and the impairments depending on the location and extent of a cerebrovascular lesion, as well as a poor response to antidepressant medication speak in favor of a vascular depression hypothesis (Alexopoulos, 2019). Several neuroimaging findings also support this hypothesis, namely amongst others - low blood flow in the precuneus, cuneus, in fronto-cingulate-striatal areas as well as temporal, occipital, and parietal lobes, a resting functional connectivity pattern as postulated in depression and changes suggesting limbic hyperactivation. Circulating markers of endothelial dysfunction and flow mediated vascular dilatation also support the vascular depression hypothesis. However, the change of depressive symptoms over time, and the fact that infarcts were not associated with the severity of depression, cannot be readily brought in line with this hypothesis (Alexopoulos, 2019). Moreover, patients suffering from ischemic lesions do not necessarily develop a depression. Epidemiological investigations focus on the comorbidity of depression and dementia with cardiovascular diseases, i.e., heart failure, however, the prognostic role of depression and the impact of heart failure as a risk factor for dementia needs further investigation (Adelborg, 2018).

\section{THE NEUROINFLAMMATION HYPOTHESIS}

Neuroinflammatory processes play an important role in the etiology of depression (Bhattacharya et al., 2016) as well as dementia (Knezevic and Mizrahi, 2018). Increased activation of microglia could be detected in depression (Setiawan et al., 2015) and in AD (Knezevic and Mizrahi, 2018). The antiinflammatory cytokine Tumor Necrosis Factor-betal (TGFbeta1) is important for memory formation and synaptic plasticity and is reduced in depression in correlation with depression severity. A deficit in TGF-betal signaling pathway is common in depression and AD (Caraci et al., 2018). In a nutshell, the inflammation hypothesis of late life depression is underpinned by typical old-age immune responses [for summary see Alexopoulos (2019)] like production of pro-inflammatory cytokines as well as reduction of anti-inflammatory molecules, the insufficient clearance of neurotoxic molecules, neuronal loss and reduced neurogenesis. Cytokines lead to (1) the induction of enzymes that reduce the production of serotonin, (2) dysregulation of the glutamate system, (3) excitotoxicity and a reduced production of neurotrophic factors that are important for neuroplasticity and neurogenesis, and (4) oxidative stress, affecting glial cells in the prefrontal cortex and the amygdala. Inflammation impairs the function of glucocorticoid receptors. The increase of inflammatory markers is associated with depression severity as well as with cognitive impairment in depression. A treatment with antidepressant medication reduces inflammation markers, as well as non-steroidal anti-inflammatory drugs might have antidepressant effects in depressive persons.

The role of the gut microbiota-brain axis in affective disorders is subject of promising interventions with pro- and prebiotics as well as fecal microbiota transplants [as reviewed by Carlessi et al. (2019) and Peirce and Alvina (2019)]. The gut microbiotabrain axis could be a common pathway in late life depression and dementia. The recent review by Panza et al. (2019c) provided evidence for a gut microbial hypothesis in dementia with the appeal to test antibacterial therapy in AD.

\section{THE NEUROTROPHIN HYPOTHESIS}

The neurotrophin BDNF is highly expressed in the central nervous system, particularly in the hippocampus where it plays a key role in the proliferation, differentiation and the maintenance of neuronal integrity throughout lifespan (Lipsky and Marini, 2007). In AD, there is an association between the rate of cognitive decline and BDNF serum levels, amyloid beta (A $\beta 1-42)$ plasma levels and the degree of platelet activation 
(activated GP IIb-IIIa and P-selectin) (Laske et al., 2010; Stellos et al., 2010; Laske et al., 2011). Furthermore, up-regulation of serum BDNF after pharmacotherapy in $\mathrm{AD}$ patients revealed a reduction of cognitive impairment and therefore could mirror a neuroprotective effect (Leyhe et al., 2008, 2009). Synaptic plasticity in neuronal networks playing a role in depression is regulated by BDNF (Schinder and Poo, 2000; Pittenger and Duman, 2008). Moreover, stress-induced deficits in structural and synaptic plasticity may be reversed by up-regulation of BDNF, enhancing cognitive flexibility and resilience against depression. Depressed and demented patients show reduced BDNF levels which are increased by antidepressant treatment (Karege et al., 2002; Shimizu et al., 2003; Aydemir et al., 2005; Gervasoni et al., 2005; Lee et al., 2006, 2011; Kim et al., 2007; Brunoni et al., 2008; Sen et al., 2008; Deuschle et al., 2013; Ricken et al., 2013). BDNF polymorphism and serum level are related to depression, anxiety, neuroticism and serotonergic neurotransmission (Hellweg et al., 2002, 2008; Lang et al., 2002, $2004,2005,2006,2007,2009)$. An augmentation with lithium is an evidence-based antidepressant therapy and leads to increasing BDNF levels (Ricken et al., 2013). Of note, a common feature among depressed patients is insomnia (Steiger and Kimura, 2010). Giese et al. (2014) present data on the relation between BDNF levels and sleep disturbances, whereas patients suffering from insomnia revealed reduced BDNF levels.

\section{THE SENESCENCE HYPOTHESIS}

Various stimuli cause cellular senescence and a senescenceassociated secretory phenotype, i.e., short/dysfunctional telomeres, non-telomeric DNA damage, oncogenes/oncogenic mutations, mitogenic/stress signals, overexpressed cell cycle inhibitors, and chromatin instability (Coppe et al., 2010). Senescence is linked to depression and could be a future therapeutic target (Diniz, 2018).

The role of telomere length and shortening as an indicator of cellular aging is discussed as a mechanism for stress-related depression (Boccardi and Boccardi, 2019) as well as for Alzheimer's dementia (Boccardi et al., 2015; Nudelman et al., 2019).

Another link for the conversion of affective disorders to dementia is glycogen synthase kinase 3 (GSK-3) that might be an etiological factor for depression and dementia (Terao et al., 2019). Lithium inhibits GSK-3 and is effective for affective disorders and cognitive impairment (Terao et al., 2006; Nunes et al., 2007; Kessing et al., 2008; Gerhard et al., 2015).

\section{THE AMYLOID HYPOTHESIS}

According to Mahgoub and Alexopoulos (2016), amyloid accumulation is related to depression by means of frontolimbic impairment. Higher plasma amyloid beta-42 predicts the development of late-life depression and conversion to AD (Blasko et al., 2010). Increased levels of amyloid beta peptides could be associated with an amyloid-related depression (Morgese et al., 2015, 2017; Schiavone et al., 2017). In elderly persons without cognitive deficits, increased amyloid burden was related to depression (Yasuno et al., 2016; Donovan et al., 2018). The amyloid hypothesis is extensively discussed as primary cause for synaptic dysfunction and neurodegeneration in $\mathrm{AD}$ (Hardy and Higgins, 1992; Hardy and Selkoe, 2002). There is a huge amount of data that supports the hypothesis that amyloid beta related toxicity plays a role in $\mathrm{AD}$ [summarized in Herrup (2015)]: For example, APOE variants are a known risk factor for $\mathrm{AD}$ and demonstrated an effect on amyloid beta clearance; overexpression of human APP in mice results in the formation of plaques; transgenic mice for human APP demonstrate memory impairment; amyloid beta shows toxicity for cultured neurons; human APP overexpressed in fruit flies leads to neurodegeneration; amyloid plaques can be detected more frequent in $\mathrm{AD}$ brains; presence of plaques is related to greater risk for developing $\mathrm{AD}$. There is, however, also a large amount of recent data underpinning that the claim for the absolute truth of this hypothesis as the primary cause for AD cannot be maintained, as summarized by Herrup (2015). Most importantly, several clinical trials with antibodies against beta amyloid based on this hypothesis failed. Solanezumab was not successful in phase 3 clinical trials (McCartney, 2015). Phase 3 clinical studies with Aducanumab were canceled in March 2019 because an interim analysis revealed that the trials were unlikely to meet the primary endpoint. However, after a reanalysis in October 2019, Biogen announced that the company intends to seek regulatory approval (Biogen, 2019). Concerning Crenezumab, Roche has recently announced discontinuation of the Phase III studies after a pre-planned interim analysis (Hoffmann-La Roche, 2019).

Amyloid beta has an important physiological role for the brain function, e.g., for neurogenesis, synaptic plasticity, memory and neuronal survival; and an overproduction of amyloid-beta might simply reflect a form of synaptic plasticity to compensate for neuronal dysfunction in different kind of neurological and psychiatric diseases of multiple etiologies, including cognitive (e.g., AD) as well as affective disorders, as reviewed by Panza et al. (2019b). This hypothesis of an amyloid beta overexpression as a compensatory attempt in terms of a repair mechanism is in line with observations that anti-amyloid beta drugs, e.g., beta-site amyloid precursor protein-cleaving enzyme 1 (BACE1) inhibitors, may induce or worsen psychiatric disturbances in cognitively impaired patients (Egan et al., 2019a,b; Henley et al., 2019; Panza et al., 2019a).

\section{THE TAU HYPOTHESIS}

Rapp et al. (2006, 2008) investigated the interaction between depression and neurofibrillary tangles in $\mathrm{AD}$ patients and indeed found increased neurofibrillary tangles in $\mathrm{AD}$ patients with a comorbid depression. However, Tsopelas et al. (2011) found that a history of late-life depression was not associated with neurofibrillary tangles in brains whose donors had no history of dementia. Longitudinal clinical-pathologic cohort studies with almost 2000 participants do not support the tau 
hypothesis that depression is associated with neurofibrillary tangles (Wilson et al., 2016).

\section{GENDER DIFFERENCES}

Gender specific associations and differences in resilience to stress (Hodes and Epperson, 2019) and in depression and dementia are widely discussed, with partly divergent results (Fuhrer et al., 2003; Kessing and Nilsson, 2003; Dal Forno et al., 2005; Simons et al., 2006; Artero et al., 2008; Chen et al., 2008; Noale et al., 2013; Mirza et al., 2014; Kim et al., 2015; Heser et al., 2020). A female to male prevalence ratio of 2:1 is described for depression (Bromet et al., 2011) and dementia (Ferretti et al., 2018). The gender differences in published prevalence rates of depression might be partly explained by the fact that men are less willing to seek psychiatric help (Kessler et al., 1981; Ferretti et al., 2018), leading to a possible underestimation of depression in men. The sex differences in life expectancy might also have an influence on the ratio for dementia. Nevertheless, sex-specific biological features, e.g., the effect of estrogens on mood and/or cognition (Kawas et al., 1997; Waring et al., 1999; Wang et al., 2000), might modulate the risk for affective and cognitive disorders. Dal Forno et al. (2005) and Heser et al. (2020) provided evidence that the association between depression and dementia is stronger in the male population.

\section{EPIGENETICS}

Several reviews exist about the role of epigenetics (meaning "on top of" genetics and without changes of DNA sequence), in the pathogenesis of depression (e.g., Menke and Binder, 2014; Nestler, 2014; Saavedra et al., 2016; Lin and Tsai, 2019) and dementia (e.g., Maloney and Lahiri, 2016; Fenoglio et al., 2018; Lemche, 2018; Stoccoro and Coppede, 2018; Sujeetha et al., 2018). To be honest, epigenetic results are fairly variable for depression and dementia, and the lack of common stable epigenetic patterns makes it difficult to relate reliable epigenetic factors in depression with the risk of $\mathrm{AD}$, as summarized by Herbert and Lucassen (2016). Further limitations addressing epigenetic research with correlational studies are discussed in the following section.

\section{LIMITATIONS}

When assessing correlational studies, it is always important to keep in mind the advantages and limitations of this approach (Asamoah, 2014): A correlation does not necessarily imply causation. Moreover, the dilemma of directionality (the "chicken-and-egg problem") cannot be sufficiently addressed by a correlational approach: It cannot be concluded that changes in variable $\mathrm{A}$ might cause changes in variable $\mathrm{B}$, but that also changes in variable B might cause changes in variable A. With respect to a multifactorial complexity of affective symptoms and cognitive impairment in humans, the variables $\mathrm{A}$ and $\mathrm{B}$ are supposed to be related to variables $\mathrm{C}, \mathrm{D}, \mathrm{E}, \ldots$.
On the other hand, causation does indeed imply a correlation. This makes it an important tool for the falsification of a hypothesis. Bearing this consideration in mind, the results of correlational studies can offer interesting ideas for further research or improved diagnostic and/or therapeutic steps. Correlational studies are extremely helpful to formulate an interesting hypothesis for experimental research. However, experimental approaches in the field of pathogenesis of depression and dementia in humans are challenging or impossible because important variables cannot be manipulated or their manipulation would be unethical. Moreover, an experimental approach using animal models for affective and cognitive diseases is limited and cannot cover all aspects of human pathology. Another challenge is the use of a representative sample and the generalization to the population of patients with depression and/or dementia.

\section{CONCLUSION}

The pathogenesis of both syndromes themselves is not understood so far - making it more difficult to describe common pathways. There is a vast amount of literature showing several potential links between dementia and depression highlighting the multifactorial complexity of both syndromes. In accordance with these multifaceted pathologies different individualized strategies (antiinflammatory, psychotherapeutic, antidepressant, antihypertensive, and endocrinological) might help to overcome the pathophysiology of dementia and depression in an individualized treatment regimen depending on the individual risk factors. However, a common drawback of all links between affective and cognitive impairments mentioned and discussed above is the lack of specificity for depression and/or dementia. When searching the literature for links between these fields, many interesting intersections can be found - but also many limitations and downsides that do not the support the respective hypotheses. To be honest, all pathways connecting dementia and late life depression that are found so far can only explain a small part of the story and have strong limitations. Correlational approaches have severe limitations, as a correlation does not necessarily imply causation. The dilemma of directionality (the "chicken-and-egg problem") as well as the third-variable problem cannot be solved. Experimental research in humans is impeded by ethical limits or the fact that certain variables cannot be manipulated. Moreover, animal models cannot address all relevant aspects of the human pathology in depression and dementia. The review of the literature shows that most publications in this field end with an outlook and perspective for prevention and/or therapy of cognitive or affective disorders that are somehow contrived and artificial hypotheses - far away from a quantum jump and breakthrough for applied therapies - due to the multifactorial complexity of both syndromes.

\section{AUTHOR CONTRIBUTIONS}

$\mathrm{CL}$ and UL performed the literature research and wrote the manuscript. 


\section{REFERENCES}

Adelborg, K. (2018). Neurological and psychiatric comorbidity in patients with heart failure: risk and prognosis. Dan. Med. J. 65:B5429.

Alexopoulos, G. S. (2019). Mechanisms and treatment of late-life depression. Transl. Psychiatry 9:188. doi: 10.1038/s41398-019-0514-6

Allison, S. L., Koscik, R. L., Cary, R. P., Jonaitis, E. M., Rowley, H. A., Chin, N. A., et al. (2019). Comparison of different MRI-based morphometric estimates for defining neurodegeneration across the Alzheimer's disease continuum. Neuroimage Clin. 23:101895. doi: 10.1016/j.nicl.2019.101895

Angulo, J. A., Ledoux, M., and McEwen, B. S. (1991). Genomic effects of cold and isolation stress on magnocellular vasopressin mRNA-containing cells in the hypothalamus of the rat. J. Neurochem. 56, 2033-2038. doi: 10.1111/j.14714159.1991.tb03463.x

Arana, G. W., and Mossman, D. (1988). The dexamethasone suppression test and depression. Approaches to the use of a laboratory test in psychiatry. Neurol. Clin. 6, 21-39. doi: 10.1016/s0733-8619(18)30882-x

Artero, S., Ancelin, M. L., Portet, F., Dupuy, A., Berr, C., Dartigues, J. F., et al. (2008). Risk profiles for mild cognitive impairment and progression to dementia are gender specific. J. Neurol. Neurosurg. Psychiatry 79, 979-984. doi: 10.1136/jnnp.2007.136903

Asamoah, M. (2014). Re-examination of the limitations associated with correlational research. J. Educ. Res. Rev. 2, 45-52.

Aydemir, O., Deveci, A., and Taneli, F. (2005). The effect of chronic antidepressant treatment on serum brain-derived neurotrophic factor levels in depressed patients: a preliminary study. Prog. Neuropsychopharmacol. Biol. Psychiatry 29, 261-265. doi: 10.1016/j.pnpbp.2004.11.009

Ballard, C., Neill, D., O’Brien, J., McKeith, I. G., Ince, P., and Perry, R. (2000). Anxiety, depression and psychosis in vascular dementia: prevalence and associations. J. Affect. Disord. 59, 97-106. doi: 10.1016/s0165-0327(99)00057-9

Bartanusz, V., Jezova, D., Bertini, L. T., Tilders, F. J., Aubry, J. M., and Kiss, J. Z. (1993). Stress-induced increase in vasopressin and corticotropin-releasing factor expression in hypophysiotrophic paraventricular neurons. Endocrinology 132, 895-902. doi: 10.1210/endo.132.2.8425502

Bhattacharya, A., Derecki, N. C., Lovenberg, T. W., and Drevets, W. C. (2016) Role of neuro-immunological factors in the pathophysiology of mood disorders. Psychopharmacology 233, 1623-1636. doi: 10.1007/s00213-016-4214-0

Biogen, I. (2019). Biogen Plans Regulatory Filing for Aducanumab in Early Alzheimer's Disease [Press Release]. Available online at: https: //biogenalzheimers.com/ (accessed December 14, 2019).

Blasko, I., Kemmler, G., Jungwirth, S., Wichart, I., Krampla, W., Weissgram, S., et al. (2010). Plasma amyloid beta-42 independently predicts both late-onset depression and Alzheimer disease. Am. J. Geriatr. Psychiatry 18, 973-982. doi: 10.1097/JGP.0b013e3181df48be

Boccardi, M., and Boccardi, V. (2019). Psychological wellbeing and healthy aging: focus on telomeres. Geriatrics 4:E25. doi: 10.3390/geriatrics4010025

Boccardi, V., Pelini, L., Ercolani, S., Ruggiero, C., and Mecocci, P. (2015). From cellular senescence to Alzheimer's disease: The role of telomere shortening. Ageing Res. Rev. 22, 1-8. doi: 10.1016/j.arr.2015.04.003

Bromet, E., Andrade, L. H., Hwang, I., Sampson, N. A., Alonso, J., de Girolamo, G., et al. (2011). Cross-national epidemiology of DSM-IV major depressive episode. BMC Med. 9:90. doi: 10.1186/1741-7015-9-90

Brunoni, A. R., Lopes, M., and Fregni, F. (2008). A systematic review and metaanalysis of clinical studies on major depression and BDNF levels: implications for the role of neuroplasticity in depression. Int. J. Neuropsychopharmacol. 11, 1169-1180. doi: 10.1017/\$1461145708009309

Butters, M. A., Young, J. B., Lopez, O., Aizenstein, H. J., Mulsant, B. H., Reynolds, C. F., et al. (2008). Pathways linking late-life depression to persistent cognitive impairment and dementia. Dialogues Clin. Neurosci. 10, 345-357.

Caraci, F., Spampinato, S. F., Morgese, M. G., Tascedda, F., Salluzzo, M. G., Giambirtone, M. C., et al. (2018). Neurobiological links between depression and AD: The role of TGF-betal signaling as a new pharmacological target. Pharmacol. Res. 130, 374-384. doi: 10.1016/j.phrs.2018.02.007

Carlessi, A. S., Borba, L. A., Zugno, A. I., Quevedo, J., and Reus, G. Z. (2019). Gut microbiota-brain axis in depression: the role of neuroinflammation. Eur. J. Neurosci. doi: 10.1111/ejn.14631 [Epub ahead of print].

Carroll, B. J., Feinberg, M., Greden, J. F., Tarika, J., Albala, A. A., Haskett, R. F., et al. (1981). A specific laboratory test for the diagnosis of melancholia.
Standardization, validation, and clinical utility. Arch. Gen. Psychiatry 38, 15-22. doi: 10.1001/archpsyc.1981.01780260017001

Cereseto, M., Reines, A., Ferrero, A., Sifonios, L., Rubio, M., and Wikinski, S. (2006). Chronic treatment with high doses of corticosterone decreases cytoskeletal proteins in the rat hippocampus. Eur. J. Neurosci. 24, 3354-3364. doi: 10.1111/j.1460-9568.2006.05232.x

Checkley, S. (1996). The neuroendocrinology of depression and chronic stress. Br. Med. Bull. 52, 597-617. doi: 10.1093/oxfordjournals.bmb.a011570

Chen, R., Hu, Z., Wei, L., Qin, X., McCracken, C., and Copeland, J. R. (2008). Severity of depression and risk for subsequent dementia: cohort studies in China and the UK. Br. J. Psychiatry 193, 373-377. doi: 10.1192/bjp.bp.107. 044974

Cho, Z. H., Kim, Y. B., Han, J. Y., Kim, N. B., Hwang, S. I., Kim, S. J., et al. (2010). Altered $\mathrm{T}^{*}$ relaxation time of the hippocampus in major depressive disorder: implications of ultra-high field magnetic resonance imaging. J. Psychiatr. Res. 44, 881-886. doi: 10.1016/j.jpsychires.2010.02.014

Cipriani, A., Furukawa, T. A., Salanti, G., Chaimani, A., Atkinson, L. Z., Ogawa, Y., et al. (2018). Comparative efficacy and acceptability of 21 antidepressant drugs for the acute treatment of adults with major depressive disorder: a systematic review and network meta-analysis. Lancet 391, 1357-1366. doi: 10.1016/S01406736(17)32802-7

Cole, J., Toga, A. W., Hojatkashani, C., Thompson, P., Costafreda, S. G., Cleare, A. J., et al. (2010). Subregional hippocampal deformations in major depressive disorder. J. Affect. Disord. 126, 272-277. doi: 10.1016/j.jad.2010.03.004

Conn, D., and Thorpe, L. (2007). Assessment of behavioural and psychological symptoms associated with dementia. Can. J. Neurol. Sci. 34(Suppl. 1), S67-S71.

Connors, M. H., Seeher, K. M., Crawford, J., Ames, D., Woodward, M. and Brodaty, H. (2018). The stability of neuropsychiatric subsyndromes in Alzheimer's disease. Alzheimers Dement 14, 880-888. doi: 10.1016/j.jalz.2018. 02.006

Coppe, J. P., Desprez, P. Y., Krtolica, A., and Campisi, J. (2010). The senescenceassociated secretory phenotype: the dark side of tumor suppression. Annu. Rev. Pathol. 5, 99-118. doi: 10.1146/annurev-pathol-121808-102144

Czeh, B., and Lucassen, P. J. (2007). What causes the hippocampal volume decrease in depression? Are neurogenesis, glial changes and apoptosis implicated? Eur. Arch. Psychiatry Clin. Neurosci. 257, 250-260. doi: 10.1007/s00406-007-0728-0

Dal Forno, G., Palermo, M. T., Donohue, J. E., Karagiozis, H., Zonderman, A. B., and Kawas, C. H. (2005). Depressive symptoms, sex, and risk for Alzheimer's disease. Ann. Neurol. 57, 381-387. doi: 10.1002/ana.20405

de Goeij, D. C., Jezova, D., and Tilders, F. J. (1992). Repeated stress enhances vasopressin synthesis in corticotropin releasing factor neurons in the paraventricular nucleus. Brain Res. 577, 165-168. doi: 10.1016/0006-8993(92) 90552-k

de Vasconcelos Cunha, U. G., Lopes Rocha, F., Avila, de Melo, R., Alves Valle, E., de Souza Neto, J. J., et al. (2007). A placebo-controlled double-blind randomized study of venlafaxine in the treatment of depression in dementia. Dement. Geriatr. Cogn. Disord 24, 36-41. doi: 10.1159/000102570

Deuschle, M., Gilles, M., Scharnholz, B., Lederbogen, F., Lang, U. E., and Hellweg, R. (2013). Changes of serum concentrations of brain-derived neurotrophic factor (BDNF) during treatment with venlafaxine and mirtazapine: role of medication and response to treatment. Pharmacopsychiatry 46, 54-58. doi: 10.1055/s-0032-1321908

Diniz, B. S. (2018). The molecular intersection between senescence and major depression in the elderly. Am. J. Geriatr. Psychiatry 26, 1097-1105. doi: 10.1016/ j.jagp.2018.07.005

Donovan, N. J., Locascio, J. J., Marshall, G. A., Gatchel, J., Hanseeuw, B. J., Rentz, D. M., et al. (2018). Longitudinal association of amyloid beta and anxiousdepressive symptoms in cognitively normal older adults. Am. J. Psychiatry 175, 530-537. doi: 10.1176/appi.ajp.2017.17040442

Dorovini-Zis, K., and Zis, A. P. (1987). Increased adrenal weight in victims of violent suicide. Am. J. Psychiatry 144, 1214-1215. doi: 10.1176/ajp.144.9.1214

Egan, M. F., Kost, J., Voss, T., Mukai, Y., Aisen, P. S., Cummings, J. L., et al. (2019a). Randomized trial of verubecestat for prodromal Alzheimer's Disease. N. Engl. J. Med. 380, 1408-1420. doi: 10.1056/NEJMoa1812840

Egan, M. F., Mukai, Y., Voss, T., Kost, J., Stone, J., Furtek, C., et al. (2019b). Further analyses of the safety of verubecestat in the phase $3 \mathrm{EPOCH}$ trial of mild-tomoderate Alzheimer's disease. Alzheimers Res Ther 11:68. doi: 10.1186/s13195019-0520-1 
Fenoglio, C., Scarpini, E., and Galimberti, D. (2018). Epigenetic regulatory modifications in genetic and sporadic frontotemporal dementia. Expert Rev Neurother 18, 469-475. doi: 10.1080/14737175.2018.1481389

Ferretti, M. T., Iulita, M. F., Cavedo, E., Chiesa, P. A., Schumacher Dimech, A., Santuccione Chadha, A., et al. (2018). Sex differences in Alzheimer disease the gateway to precision medicine. Nat. Rev. Neurol. 14, 457-469. doi: 10.1038/ s41582-018-0032-9

Ferri, C. P., Prince, M., Brayne, C., Brodaty, H., Fratiglioni, L., Ganguli, M., et al. (2005). Global prevalence of dementia: a Delphi consensus study. Lancet 366, 2112-2117. doi: 10.1016/S0140-6736(05)67889-0

Fuhrer, R., Dufouil, C., Dartigues, J. F., and Study, P. (2003). Exploring sex differences in the relationship between depressive symptoms and dementia incidence: prospective results from the PAQUID Study. J. Am. Geriatr. Soc. 51, 1055-1063. doi: 10.1046/j.1532-5415.2003.51352.x

Gallagher, D., Mhaolain, A. N., Greene, E., Walsh, C., Denihan, A., Bruce, I., et al. (2010). Late life depression: a comparison of risk factors and symptoms according to age of onset in community dwelling older adults. Int. J. Geriatr. Psychiatry 25, 981-987. doi: 10.1002/gps.2438

Gerhard, T., Devanand, D. P., Huang, C., Crystal, S., and Olfson, M. (2015). Lithium treatment and risk for dementia in adults with bipolar disorder: population-based cohort study. Br. J. Psychiatry 207, 46-51. doi: 10.1192/bjp. bp.114.154047

Gervasoni, N., Aubry, J. M., Bondolfi, G., Osiek, C., Schwald, M., Bertschy, G., et al. (2005). Partial normalization of serum brain-derived neurotrophic factor in remitted patients after a major depressive episode. Neuropsychobiology 51, 234-238. doi: 10.1159/000085725

Giese, M., Unternahrer, E., Huttig, H., Beck, J., Brand, S., Calabrese, P., et al. (2014). BDNF: an indicator of insomnia? Mol. Psychiatry 19, 151-152. doi: $10.1038 / \mathrm{mp} .2013 .10$

Gould, E., Tanapat, P., Rydel, T., and Hastings, N. (2000). Regulation of hippocampal neurogenesis in adulthood. Biol. Psychiatry 48, 715-720. doi: 10. 1016/s0006-3223(00)01021-0

Hamilton, M. (1960). A rating scale for depression. J. Neurol. Neurosurg. Psychiatry 23, 56-62. doi: 10.1136/jnnp.23.1.56

Han, K. M., Won, E., Sim, Y., and Tae, W. S. (2016). Hippocampal subfield analysis in medication-naive female patients with major depressive disorder. J. Affect. Disord. 194, 21-29. doi: 10.1016/j.jad.2016.01.019

Harbuz, M. S., Leonard, J. P., Lightman, S. L., and Cuzner, M. L. (1993). Changes in hypothalamic corticotrophin-releasing factor and anterior pituitary pro-opiomelanocortin mRNA during the course of experimental allergic encephalomyelitis. J. Neuroimmunol. 45, 127-132. doi: 10.1016/0165-5728(93) 90172-u

Hardy, J., and Selkoe, D. J. (2002). The amyloid hypothesis of Alzheimer's disease: progress and problems on the road to therapeutics. Science 297, 353-356. doi: 10.1126/science. 1072994

Hardy, J. A., and Higgins, G. A. (1992). Alzheimer's disease: the amyloid cascade hypothesis. Science 256, 184-185. doi: 10.1126/science.1566067

Hellweg, R., Lang, U. E., Nagel, M., and Baumgartner, A. (2002). Subchronic treatment with lithium increases nerve growth factor content in distinct brain regions of adult rats. Mol. Psychiatry 7, 604-608. doi: 10.1038/sj.mp.4001042

Hellweg, R., Ziegenhorn, A., Heuser, I., and Deuschle, M. (2008). Serum concentrations of nerve growth factor and brain-derived neurotrophic factor in depressed patients before and after antidepressant treatment. Pharmacopsychiatry 41, 66-71. doi: 10.1055/s-2007-1004594

Henley, D., Raghavan, N., Sperling, R., Aisen, P., Raman, R., and Romano, G. (2019). Preliminary results of a trial of atabecestat in preclinical Alzheimer's Disease. N. Engl. J. Med. 380, 1483-1485. doi: 10.1056/NEJMc181 3435

Herbert, J., and Lucassen, P. J. (2016). Depression as a risk factor for Alzheimer's disease: genes, steroids, cytokines and neurogenesis - what do we need to know? Front. Neuroendocrinol. 41:153-171. doi: 10.1016/j.yfrne.2015.12.001

Herman, J. P., Adams, D., and Prewitt, C. (1995). Regulatory changes in neuroendocrine stress-integrative circuitry produced by a variable stress paradigm. Neuroendocrinology 61, 180-190. doi: 10.1159/000126839

Herman, J. P., Schafer, M. K., Young, E. A., Thompson, R., Douglass, J., Akil, H., et al. (1989). Evidence for hippocampal regulation of neuroendocrine neurons of the hypothalamo-pituitary-adrenocortical axis. J. Neurosci. 9, 3072-3082. doi: 10.1523/jneurosci.09-09-03072.1989
Herrup, K. (2015). The case for rejecting the amyloid cascade hypothesis. Nat. Neurosci. 18, 794-799. doi: 10.1038/nn.4017

Heser, K., Kleineidam, L., Pabst, A., Wiese, B., Roehr, S., Lobner, M., et al. (2020). Sex-Specific Associations Between Depressive Symptoms and Risk for Subsequent Dementia. J. Alzheimers Dis. doi: 10.3233/JAD-19 0770 [Epub ahead of print].

Hodes, G. E., and Epperson, C. N. (2019). Sex Differences in Vulnerability and Resilience to Stress Across the Life Span. Biol. Psychiatry 86, 421-432. doi: 10.1016/j.biopsych.2019.04.028

Hoffmann-La Roche, L. F. (2019). Roche to Discontinue Phase III CREAD 1 and 2 Clinical Studies of Crenezumab in Early Alzheimer's disease (AD) Other Company Programmes in AD Continue [Press Release]. Available online at: https://www.roche.com/media/releases/med-cor-2019-01-30.htm (accessed December 14, 2019).

Holroyd, S., and Clayton, A. H. (2000). Measuring depression in the elderly: which scale is best?. Medscape. Gen. Med. 5:9.

Huang, Y., Coupland, N. J., Lebel, R. M., Carter, R., Seres, P., Wilman, A. H., et al. (2013). Structural changes in hippocampal subfields in major depressive disorder: a high-field magnetic resonance imaging study. Biol. Psychiatry 74, 62-68. doi: 10.1016/j.biopsych.2013.01.005

Kalaria, R. N., Maestre, G. E., Arizaga, R., Friedland, R. P., Galasko, D., Hall, K., et al. (2008). Alzheimer's disease and vascular dementia in developing countries: prevalence, management, and risk factors. Lancet Neurol. 7, 812-826. doi: 10.1016/S1474-4422(08)70169-8

Karege, F., Perret, G., Bondolfi, G., Schwald, M., Bertschy, G., and Aubry, J. M. (2002). Decreased serum brain-derived neurotrophic factor levels in major depressed patients. Psychiatry Res. 109, 143-148. doi: 10.1016/s0165-1781(02) 00005-7

Kawas, C., Resnick, S., Morrison, A., Brookmeyer, R., Corrada, M., Zonderman, A., et al. (1997). A prospective study of estrogen replacement therapy and the risk of developing Alzheimer's disease: the baltimore longitudinal study of aging. Neurology 48, 1517-1521. doi: 10.1212/wnl.48.6.1517

Kessing, L. V., and Nilsson, F. M. (2003). Increased risk of developing dementia in patients with major affective disorders compared to patients with other medical illnesses. J. Affect. Disord. 73, 261-269. doi: 10.1016/s0165-0327(02)00004-6

Kessing, L. V., Sondergard, L., Forman, J. L., and Andersen, P. K. (2008). Lithium treatment and risk of dementia. Arch. Gen. Psychiatry 65, 1331-1335. doi: 10.1001/archpsyc.65.11.1331

Kessler, R. C., Brown, R. L., and Broman, C. L. (1981). Sex differences in psychiatric help-seeking: evidence from four large-scale surveys. J. Health Soc. Behav. 22, 49-64.

Khundakar, A. A., and Thomas, A. J. (2015). Neuropathology of depression in Alzheimer's disease: current knowledge and the potential for new treatments. J. Alzheimers. Dis. 44, 27-41. doi: 10.3233/JAD-148003

Kim, S., Kim, M. J., Kim, S., Kang, H. S., Lim, S. W., Myung, W., et al. (2015). Gender differences in risk factors for transition from mild cognitive impairment to Alzheimer's disease: A CREDOS study. Compr. Psychiatry 62, 114-122. doi: 10.1016/j.comppsych.2015.07.002

Kim, Y. K., Lee, H. P., Won, S. D., Park, E. Y., Lee, H. Y., Lee, B. H., et al. (2007). Low plasma BDNF is associated with suicidal behavior in major depression. Prog. Neuropsychopharmacol. Biol. Psychiatry 31, 78-85. doi: 10.1016/j.pnpbp.2006. 06.024

Knezevic, D., and Mizrahi, R. (2018). Molecular imaging of neuroinflammation in Alzheimer's disease and mild cognitive impairment. Prog. Neuropsychopharmacol. Biol. Psychiatry 80(Pt B), 123-131. doi: 10.1016/j.pnpbp.2017.05.007

Lang, U. E., Bajbouj, M., Gallinat, J., and Hellweg, R. (2006). Brain-derived neurotrophic factor serum concentrations in depressive patients during vagus nerve stimulation and repetitive transcranial magnetic stimulation. Psychopharmacology 187, 56-59. doi: 10.1007/s00213-006-0399-y

Lang, U. E., Gallinat, J., Kuhn, S., Jockers-Scherubl, M. C., and Hellweg, R. (2002). Nerve growth factor and smoking cessation. Am. J. Psychiatry 159, 674-675.

Lang, U. E., Gunther, L., Scheuch, K., Klein, J., Eckhart, S., Hellweg, R., et al. (2009). Higher BDNF concentrations in the hippocampus and cortex of an aggressive mouse strain. Behav. Brain Res. 197, 246-249. doi: 10.1016/j.bbr.2008.08.025

Lang, U. E., Hellweg, R., and Gallinat, J. (2004). BDNF serum concentrations in healthy volunteers are associated with depression-related personality traits. Neuropsychopharmacology 29, 795-798. doi: 10.1038/sj.npp.1300382 
Lang, U. E., Hellweg, R., and Gallinat, J. (2005). Association of BDNF serum concentrations with central serotonergic activity: evidence from auditory signal processing. Neuropsychopharmacology 30, 1148-1153. doi: 10.1038/sj. npp. 1300666

Lang, U. E., Hellweg, R., Seifert, F., Schubert, F., and Gallinat, J. (2007). Correlation between serum brain-derived neurotrophic factor level and an in vivo marker of cortical integrity. Biol. Psychiatry 62, 530-535. doi: 10.1016/j.biopsych.2007. 01.002

Laske, C., Sopova, K., Gkotsis, C., Eschweiler, G. W., Straten, G., Gawaz, M., et al. (2010). Amyloid-beta peptides in plasma and cognitive decline after 1 year follow-up in Alzheimer's disease patients. J. Alzheimers. Dis. 21, 1263-1269. doi: 10.3233/jad-2010-100510

Laske, C., Stellos, K., Hoffmann, N., Stransky, E., Straten, G., Eschweiler, G. W., et al. (2011). Higher BDNF serum levels predict slower cognitive decline in Alzheimer's disease patients. Int. J. Neuropsychopharmacol. 14, 399-404. doi: $10.1017 /$ S1461145710001008

Laske, C., Stransky, E., Fritsche, A., Eschweiler, G. W., and Leyhe, T. (2009). Inverse association of cortisol serum levels with T-tau, P-tau 181 and P-tau 231 peptide levels and T-tau/Abeta 1-42 ratios in CSF in patients with mild Alzheimer's disease dementia. Eur. Arch. Psychiatry Clin. Neurosci. 259, 80-85. doi: $10.1007 / \mathrm{s} 00406-008-0838-3$

Lee, A. H., Lange, C., Ricken, R., Hellweg, R., and Lang, U. E. (2011). Reduced brain-derived neurotrophic factor serum concentrations in acute schizophrenic patients increase during antipsychotic treatment. J. Clin. Psychopharmacol. 31, 334-336. doi: 10.1097/JCP.0b013e31821895c1

Lee, R. C., Hammell, C. M., and Ambros, V. (2006). Interacting endogenous and exogenous RNAi pathways in Caenorhabditis elegans. RNA 12, 589-597. doi: 10.1261/rna.2231506

Lemche, E. (2018). Early Life Stress and Epigenetics in Late-onset Alzheimer's Dementia: A Systematic Review. Curr. Genomics 19, 522-602. doi: 10.2174/ 1389202919666171229145156

Lenoir, H., Dufouil, C., Auriacombe, S., Lacombe, J. M., Dartigues, J. F., Ritchie, K., et al. (2011). Depression history, depressive symptoms, and incident dementia: the 3C Study. J. Alzheimers. Dis. 26, 27-38. doi: 10.3233/JAD-2011-10 1614

Leong, C. (2014). Antidepressants for depression in patients with dementia: a review of the literature. Consult. Pharm. 29, 254-263. doi: 10.4140/TCP.n.2014. 254

Levy, A., Dachir, S., Arbel, I., and Kadar, T. (1994). Aging, stress, and cognitive function. Ann. N. Y. Acad. Sci. 717, 79-88. doi: 10.1111/j.1749-6632.1994. tb12075.x

Leyhe, T., Eschweiler, G. W., Stransky, E., Gasser, T., Annas, P., Basun, H., et al. (2009). Increase of BDNF serum concentration in lithium treated patients with early Alzheimer's disease. J. Alzheimers. Dis. 16, 649-656. doi: 10.3233/JAD2009-1004

Leyhe, T., Reynolds, C. F. III, Melcher, T., Linnemann, C., Kloppel, S., Blennow, $\mathrm{K}$., et al. (2017). A common challenge in older adults: classification, overlap, and therapy of depression and dementia. Alzheimers Dement 13, 59-71. doi: 10.1016/j.jalz.2016.08.007

Leyhe, T., Stransky, E., Eschweiler, G. W., Buchkremer, G., and Laske, C. (2008). Increase of BDNF serum concentration during donepezil treatment of patients with early Alzheimer's disease. Eur. Arch. Psychiatry Clin. Neurosci. 258, 124128. doi: 10.1007/s00406-007-0764-9

Lichtenberg, P. A., Marcopulos, B. A., Steiner, D. A., and Tabscott, J. A. (1992). Comparison of the Hamilton depression rating scale and the geriatric depression scale: detection of depression in dementia patients. Psychol. Rep. 70, 515-521. doi: 10.2466/pr0.1992.70.2.515

Lin, E., and Tsai, S. J. (2019). Epigenetics and depression: an update. Psychiatry Investig. 16, 654-661. doi: 10.30773/pi.2019.07.17.2

Lindqvist, D., Mueller, S., Mellon, S. H., Su, Y., Epel, E. S., Reus, V. I., et al. (2014). Peripheral antioxidant markers are associated with total hippocampal and CA3/dentate gyrus volume in MDD and healthy controls-preliminary findings. Psychiatry Res. 224, 168-174. doi: 10.1016/j.pscychresns.2014. 09.002

Lipsky, R. H., and Marini, A. M. (2007). Brain-derived neurotrophic factor in neuronal survival and behavior-related plasticity. Ann. N. Y. Acad. Sci. 1122, 130-143. doi: 10.1196/annals.1403.009
Lopez, O. L., Becker, J. T., Sweet, R. A., Klunk, W., Kaufer, D. I., Saxton, J., et al. (2003). Psychiatric symptoms vary with the severity of dementia in probable Alzheimer's disease. J. Neuropsychiatry Clin. Neurosci. 15, 346-353. doi: 10. 1176/jnp.15.3.346

Mahgoub, N., and Alexopoulos, G. S. (2016). Amyloid hypothesis: is there a role for antiamyloid treatment in late-life depression? Am. J. Geriatr. Psychiatry 24, 239-247. doi: 10.1016/j.jagp.2015.12.003

Maller, J. J., Broadhouse, K., Rush, A. J., Gordon, E., Koslow, S., and Grieve, S. M. (2018). Increased hippocampal tail volume predicts depression status and remission to anti-depressant medications in major depression. Mol. Psychiatry 23, 1737-1744. doi: 10.1038/mp.2017.224

Maloney, B., and Lahiri, D. K. (2016). Epigenetics of dementia: understanding the disease as a transformation rather than a state. Lancet Neurol. 15, 760-774. doi: 10.1016/S1474-4422(16)00065-X

McCartney, M. (2015). Margaret McCartney: The "breakthrough" drug that's not been shown to help in Alzheimer's disease. BMJ 351:h4064. doi: 10.1136/bmj. h4064

McEwen, B. S. (1999). Stress and the aging hippocampus. Front. Neuroendocrinol. 20:49-70. doi: 10.1006/frne.1998.0173

Menke, A., and Binder, E. B. (2014). Epigenetic alterations in depression and antidepressant treatment. Dialogues Clin. Neurosci. 16, 395-404.

Mirza, S. S., de Bruijn, R. F., Direk, N., Hofman, A., Koudstaal, P. J., Ikram, M. A., et al. (2014). Depressive symptoms predict incident dementia during short- but not long-term follow-up period. Alzheimers Dement, 10(5 Suppl), S323.e1-S 329.e1. doi: 10.1016/j.jalz.2013.10.006

Montgomery, S. A., and Asberg, M. (1979). A new depression scale designed to be sensitive to change. Br. J. Psychiatry 134, 382-389. doi: 10.1192/bjp.134. 4.382

Morgese, M. G., Colaianna, M., Mhillaj, E., Zotti, M., Schiavone, S., D’Antonio, P., et al. (2015). Soluble beta amyloid evokes alteration in brain norepinephrine levels: role of nitric oxide and interleukin-1. Front. Neurosci. 9:428. doi: 10.3389/ fnins.2015.00428

Morgese, M. G., Schiavone, S., and Trabace, L. (2017). Emerging role of amyloid beta in stress response: Implication for depression and diabetes. Eur. J. Pharmacol 817, 22-29. doi: 10.1016/j.ejphar.2017.08.031

Na, K. S., Chang, H. S., Won, E., Han, K. M., Choi, S., Tae, W. S., et al. (2014). Association between glucocorticoid receptor methylation and hippocampal subfields in major depressive disorder. PLoS One 9:e85425. doi: 10.1371/journal. pone. 0085425

Nemeroff, C. B., Krishnan, K. R., Reed, D., Leder, R., Beam, C., and Dunnick, N. R. (1992). Adrenal gland enlargement in major depression. A computed tomographic study. Arch. Gen. Psychiatry 49, 384-387. doi: 10.1001/archpsyc. 1992.01820050048008

Nestler, E. J. (2014). Epigenetic mechanisms of depression. JAMA Psychiatry 71, 454-456. doi: 10.1001/jamapsychiatry.2013.4291

Noale, M., Limongi, F., Zambon, S., Crepaldi, G., Maggi, S., and Group, I. W. (2013). Incidence of dementia: evidence for an effect modification by gender. The ILSA Study. Int. Psychogeriatr. 25, 1867-1876. doi: 10.1017/ S1041610213001300

Nudelman, K. N. H., Lin, J., Lane, K. A., Nho, K., Kim, S., Faber, K. M., et al. (2019). Telomere shortening in the Alzheimer's Disease neuroimaging initiative cohort. J. Alzheimers. Dis. 71, 33-43. doi: 10.3233/JAD-190010

Nunes, P. V., Forlenza, O. V., and Gattaz, W. F. (2007). Lithium and risk for Alzheimer's disease in elderly patients with bipolar disorder. Br. J. Psychiatry 190, 359-360. doi: 10.1192/bjp.bp.106.029868

Panza, F., Lozupone, M., Bellomo, A., and Imbimbo, B. P. (2019a). Do anti-amyloid-beta drugs affect neuropsychiatric status in Alzheimer's disease patients? Ageing Res. Rev. 55:100948. doi: 10.1016/j.arr.2019.10 0948

Panza, F., Lozupone, M., Logroscino, G., and Imbimbo, B. P. (2019b). A critical appraisal of amyloid-beta-targeting therapies for Alzheimer disease. Nat. Rev. Neurol. 15, 73-88. doi: 10.1038/s41582-018-0116-6

Panza, F., Lozupone, M., Solfrizzi, V., Watling, M., and Imbimbo, B. P. (2019c). Time to test antibacterial therapy in Alzheimer's disease. Brain 142, 2905-2929. doi: 10.1093/brain/awz244

Park, J. H., Lee, S. B., Lee, T. J., Lee, D. Y., Jhoo, J. H., Youn, J. C., et al. (2007). Depression in vascular dementia is quantitatively and qualitatively different 
from depression in Alzheimer's disease. Dement. Geriatr. Cogn. Disord. 23, 67-73. doi: 10.1159/000097039

Peirce, J. M., and Alvina, K. (2019). The role of inflammation and the gut microbiome in depression and anxiety. J. Neurosci. Res. 97, 1223-1241. doi: 10.1002/jnr.24476

Petracca, G. M., Chemerinski, E., and Starkstein, S. E. (2001). A double-blind, placebo-controlled study of fluoxetine in depressed patients with Alzheimer's disease. Int. Psychogeriatr. 13, 233-240. doi: 10.1017/s104161020100 $761 x$

Pittenger, C., and Duman, R. S. (2008). Stress, depression, and neuroplasticity: a convergence of mechanisms. Neuropsychopharmacology 33, 88-109. doi: 10. 1038/sj.npp.1301574

Porcelli, S., Fabbri, C., Spina, E., Serretti, A., and De Ronchi, D. (2011). Genetic polymorphisms of cytochrome P450 enzymes and antidepressant metabolism. Expert. Opin. Drug. Metab. Toxicol. 7, 1101-1115. doi: 10.1517/17425255.2011. 597740

Raadsheer, F. C., Hoogendijk, W. J., Stam, F. C., Tilders, F. J., and Swaab, D. F. (1994). Increased numbers of corticotropin-releasing hormone expressing neurons in the hypothalamic paraventricular nucleus of depressed patients. Neuroendocrinology 60, 436-444. doi: 10.1159/000126778

Rapp, M. A., Schnaider-Beeri, M., Grossman, H. T., Sano, M., Perl, D. P., Purohit, D. P., et al. (2006). Increased hippocampal plaques and tangles in patients with Alzheimer disease with a lifetime history of major depression. Arch. Gen. Psychiatry 63, 161-167. doi: 10.1001/archpsyc.63.2.161

Rapp, M. A., Schnaider-Beeri, M., Purohit, D. P., Perl, D. P., Haroutunian, V., and Sano, M. (2008). Increased neurofibrillary tangles in patients with Alzheimer disease with comorbid depression. Am. J. Geriatr. Psychiatry 16, 168-174. doi: 10.1097/JGP.0b013e31816029ec

Reifler, B. V., Teri, L., Raskind, M., Veith, R., Barnes, R., White, E., et al. (1989). Double-blind trial of imipramine in Alzheimer's disease patients with and without depression. Am. J. Psychiatry 146, 45-49. doi: 10.1176/ajp.146. 1.45

Ricken, R., Adli, M., Lange, C., Krusche, E., Stamm, T. J., Gaus, S., et al. (2013). Brain-derived neurotrophic factor serum concentrations in acute depressive patients increase during lithium augmentation of antidepressants. J. Clin. Psychopharmacol. 33, 806-809. doi: 10.1097/JCP.0b013e3182a4 $12 \mathrm{~b} 8$

Rubin, R. T., Phillips, J. J., Sadow, T. F., and McCracken, J. T. (1995). Adrenal gland volume in major depression. Increase during the depressive episode and decrease with successful treatment. Arch. Gen. Psychiatry 52, 213-218. doi: 10.1001/archpsyc.1995.03950150045009

Saavedra, K., Molina-Marquez, A. M., Saavedra, N., Zambrano, T., and Salazar, L. A. (2016). Epigenetic modifications of major depressive disorder. Int. J. Mol. Sci. 17:E1279. doi: 10.3390/ijms17081279

Sapolsky, R. M., Krey, L. C., and McEwen, B. S. (1984). Stress down-regulates corticosterone receptors in a site-specific manner in the brain. Endocrinology 114, 287-292. doi: 10.1210/endo-114-1-287

Schiavone, S., Tucci, P., Mhillaj, E., Bove, M., Trabace, L., and Morgese, M. G. (2017). Antidepressant drugs for beta amyloid-induced depression: a new standpoint? Prog. Neuropsychopharmacol. Biol. Psychiatry 78, 114-122. doi: 10.1016/j.pnpbp.2017.05.004

Schinder, A. F., and Poo, M. (2000). The neurotrophin hypothesis for synaptic plasticity. Trends Neurosci. 23, 639-645. doi: 10.1016/s0166-2236(00)01 672-6

Sen, S., Duman, R., and Sanacora, G. (2008). Serum brain-derived neurotrophic factor, depression, and antidepressant medications: meta-analyses and implications. Biol. Psychiatry 64, 527-532. doi: 10.1016/j.biopsych.2008.05.005

Setiawan, E., Wilson, A. A., Mizrahi, R., Rusjan, P. M., Miler, L., Rajkowska, G., et al. (2015). Role of translocator protein density, a marker of neuroinflammation, in the brain during major depressive episodes. JAMA Psychiatry 72, 268-275. doi: 10.1001/jamapsychiatry.2014.2427

Shimizu, E., Hashimoto, K., Okamura, N., Koike, K., Komatsu, N., Kumakiri, C., et al. (2003). Alterations of serum levels of brain-derived neurotrophic factor (BDNF) in depressed patients with or without antidepressants. Biol. Psychiatry 54, 70-75. doi: 10.1016/s0006-3223(03)00181-1

Simons, L. A., Simons, J., McCallum, J., and Friedlander, Y. (2006). Lifestyle factors and risk of dementia: Dubbo Study of the elderly. Med. J. Aust. 184, 68-70. doi: 10.5694/j.1326-5377.2006.tb00120.x
Steffens, D. C., and Potter, G. G. (2008). Geriatric depression and cognitive impairment. Psychol. Med. 38, 163-175. doi: 10.1017/S003329170700102X

Steiger, A., and Kimura, M. (2010). Wake and sleep EEG provide biomarkers in depression. J. Psychiatr. Res. 44, 242-252. doi: 10.1016/j.jpsychires.2009.08.013

Steinberg, M., Shao, H., Zandi, P., Lyketsos, C. G., Welsh-Bohmer, K. A., Norton, M. C., et al. (2008). Point and 5-year period prevalence of neuropsychiatric symptoms in dementia: the cache county Study. Int. J. Geriatr. Psychiatry 23, 170-177. doi: 10.1002/gps.1858

Stellos, K., Panagiota, V., Kogel, A., Leyhe, T., Gawaz, M., and Laske, C. (2010). Predictive value of platelet activation for the rate of cognitive decline in Alzheimer's disease patients. J. Cereb. Blood Flow Metab. 30, 1817-1820. doi: 10.1038/jcbfm.2010.140

Stoccoro, A., and Coppede, F. (2018). Role of epigenetics in Alzheimer's disease pathogenesis. Neurodegener. Dis. Manag. 8, 181-193. doi: 10.2217/nmt-20180004

Sujeetha, P., Cheerian, J., Basavaraju, P., Moorthi, P., and Anand, A. (2018). The role of epigenetics in Alzheimer\&\#39;s disease. J Geriatr. Mental Health 5, 94-98. doi: 10.4103/jgmh.jgmh_33_17

Terao, T., Ishii, N., and Hirakawa, H. (2019). A specific group of patients with diagnostic conversion from depression to bipolar disorder and finally to dementia as a mental GSK-3 disease: a hypothesis. Bipolar. Disord. doi: 10.1111/ bdi.12875 [Epub ahead of print].

Terao, T., Nakano, H., Inoue, Y., Okamoto, T., Nakamura, J., and Iwata, N. (2006). Lithium and dementia: a preliminary study. Prog. Neuropsychopharmacol. Biol. Psychiatry 30, 1125-1128. doi: 10.1016/j.pnpbp.2006.04.020

Travis, S., Coupland, N. J., Silversone, P. H., Huang, Y., Fujiwara, E., Carter, R., et al. (2015). Dentate gyrus volume and memory performance in major depressive disorder. J. Affect. Disord. 172, 159-164. doi: 10.1016/j.jad.2014. 09.048

Treadway, M. T., Waskom, M. L., Dillon, D. G., Holmes, A. J., Park, M. T. M., Chakravarty, M. M., et al. (2015). Illness progression, recent stress, and morphometry of hippocampal subfields and medial prefrontal cortex in major depression. Biol. Psychiatry 77, 285-294. doi: 10.1016/j.biopsych.2014.06.018

Tsopelas, C., Stewart, R., Savva, G. M., Brayne, C., Ince, P., Thomas, A., et al. (2011). Neuropathological correlates of late-life depression in older people. $\mathrm{Br}$. J. Psychiatry 198, 109-114. doi: 10.1192/bjp.bp.110.078816

Ur, E., Dinan, T. G., O’Keane, V., Clare, A. W., McLoughlin, L., Rees, L. H., et al. (1992). Effect of metyrapone on the pituitary-adrenal axis in depression: relation to dexamethasone suppressor status. Neuroendocrinology 56, 533-538. doi: $10.1159 / 000126271$

van der Flier, W. M., and Scheltens, P. (2005). Epidemiology and risk factors of dementia. J. Neurol. Neurosurg. Psychiatry 76(Suppl. 5), v2-v7. doi: 10.1136/ jnnp.2005.082867

van der Linde, R. M., Dening, T., Stephan, B. C., Prina, A. M., Evans, E., and Brayne, C. (2016). Longitudinal course of behavioural and psychological symptoms of dementia: systematic review. Br. J. Psychiatry 209, 366-377. doi: 10.1192/bjp.bp. 114.148403

Vik-Mo, A. O., Giil, L. M., Ballard, C., and Aarsland, D. (2018). Course of neuropsychiatric symptoms in dementia: 5-year longitudinal study. Int. J. Geriatr. Psychiatry 33, 1361-1369. doi: 10.1002/gps.4933

Wang, P. N., Liao, S. Q., Liu, R. S., Liu, C. Y., Chao, H. T., Lu, S. R., et al. (2000). Effects of estrogen on cognition, mood, and cerebral blood flow in AD: a controlled study. Neurology 54, 2061-2066. doi: 10.1212/wnl.54.11. 2061

Waring, S. C., Rocca, W. A., Petersen, R. C., O’Brien, P. C., Tangalos, E. G., and Kokmen, E. (1999). Postmenopausal estrogen replacement therapy and risk of AD: a population-based study. Neurology 52, 965-970. doi: 10.1212/wnl.52.5. 965

Weiner, M. F., Doody, R. S., Sairam, R., Foster, B., and Liao, T. Y. (2002). Prevalence and incidence of major depressive disorder in Alzheimer's disease: findings from two databases. Dement. Geriatr. Cogn. Disord. 13, 8-12. doi: 10.1159/ 000048627

Weiner, M. F., Edland, S. D., and Luszczynska, H. (1994). Prevalence and incidence of major depression in Alzheimer's disease. Am. J. Psychiatry 151, 1006-1009. doi: 10.1176/ajp.151.7.1006

Wilson, R. S., Boyle, P. A., Capuano, A. W., Shah, R. C., Hoganson, G. M., Nag, S., et al. (2016). Late-life depression is not associated with dementia-related pathology. Neuropsychology 30, 135-142. doi: 10.1037/neu0000223 
Yasuno, F., Kazui, H., Morita, N., Kajimoto, K., Ihara, M., Taguchi, A., et al. (2016). High amyloid-beta deposition related to depressive symptoms in older individuals with normal cognition: a pilot study. Int. J. Geriatr. Psychiatry 31, 920-928. doi: 10.1002/gps.4409

Young, E. A., Haskett, R. F., Grunhaus, L., Pande, A., Weinberg, V. M., Watson, S. J., et al. (1994). Increased evening activation of the hypothalamic-pituitaryadrenal axis in depressed patients. Arch. Gen. Psychiatry 51, 701-707. doi: 10.1001/archpsyc.1994.03950090033005

Young, E. A., Haskett, R. F., Murphy-Weinberg, V., Watson, S. J., and Akil, H. (1991). Loss of glucocorticoid fast feedback in depression. Arch. Gen. Psychiatry 48, 693-699. doi: 10.1001/archpsyc.1991.01810320017003

Young, E. A., Spencer, R. L., and McEwen, B. S. (1990). Changes at multiple levels of the hypothalamo-pituitary adrenal axis following repeated electrically induced seizures. Psychoneuroendocrinology 15, 165-172. doi: 10.1016/0306-4530(90) 90027-7
Zubenko, G. S., Zubenko, W. N., McPherson, S., Spoor, E., Marin, D. B., Farlow, M. R., et al. (2003). A collaborative study of the emergence and clinical features of the major depressive syndrome of Alzheimer's disease. Am. J. Psychiatry 160, 857-866. doi: 10.1176/appi.ajp.160.5.857

Conflict of Interest: The authors declare that the research was conducted in the absence of any commercial or financial relationships that could be construed as a potential conflict of interest.

Copyright (c) 2020 Linnemann and Lang. This is an open-access article distributed under the terms of the Creative Commons Attribution License (CC BY). The use, distribution or reproduction in other forums is permitted, provided the original author(s) and the copyright owner(s) are credited and that the original publication in this journal is cited, in accordance with accepted academic practice. No use, distribution or reproduction is permitted which does not comply with these terms. 